\title{
High-flow nasal cannula for body rewarming in hypothermia
}

\author{
Emanuele Gilardi ${ }^{1}$, Martina Petrucci ${ }^{1}$, Luca Sabia ${ }^{1}$, Kidane Wolde Sellasie ${ }^{1}$, Domenico Luca Grieco ${ }^{1,2^{*}}$ (D) and \\ Mariano Alberto Pennisi ${ }^{1,2}$
}

Keywords: High-flow nasal cannula, Hypothermia

\section{Dear Editor,}

Use of high-flow nasal cannula (HFNC) is common in critically ill patients with or at risk of respiratory failure. Its benefits include accurate delivery of the set fraction of inspired oxygen $\left(\mathrm{FiO}_{2}\right)$, carbon dioxide washout from nasopharyngeal dead space, provision of small degree of positive end-expiratory pressure, and improved tolerance due to the comfortable interface [1-3]. To continuously deliver flows up to $60 \mathrm{l} / \mathrm{min}$, inspired gas is actively conditioned through a heated humidifier, which increases gas temperature and absolute humidity up to $37^{\circ} \mathrm{C}$ and $44 \mathrm{mgH}_{2} \mathrm{O} / \mathrm{l}$.

Airway warming (i.e., respiratory insulation) is a technique previously described to treat hypothermia [4]. In the lungs, the surface available for heat exchange is that of pulmonary havens, with a total area of about 100$140 \mathrm{~m}^{2}$. Moreover, inhalation of heated air yields vasodilation of alveolar capillaries, which further increases the surface for heat exchange between the blood and alveolar gas. Full humidification of inhaled air enhances heat transfer and conduction $[4,5]$.

Over a 6-month period (October 2018-March 2019), we applied, for clinical purposes, HFNC with no oxygen supplementation to 4 patients ( 3 females, median [interquartile range] age 51 [67-86] years), who were admitted to the emergency department of our institution with stage 1-2 primary hypothermia (i.e., prolonged exposure to cold environment)

\footnotetext{
* Correspondence: dlgrieco@outlook.it

'Scienze dell'emergenza, anestesiologiche e della rianimazione, Fondazione Policlinico Universitario A. Gemelli IRCCS, L.go F.Vito, 00168 Rome, Italy ${ }^{2}$ Istituto di Anestesiologia e Rianimazione, Università Cattolica del Sacro Cuore, Rome, Italy
}

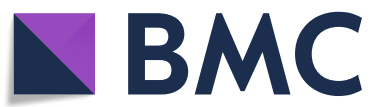

[6]. All patients were fully awake, hemodynamically stable, and had no respiratory distress nor gas exchange impairment. HFNC was administered through the AIRVO 2 device (Fisher and Paykel healthcare, New Zealand) or by a gas-compressed mechanical ventilator (EvitaXL or EvitaInfinity, Draeger, Lubeck, Germany) through a heated humidifier (MR860, Fisher and Paykel Healthcare, New Zealand): gas flow was set at $50-60 \mathrm{l} / \mathrm{min}$, humidification chamber at $37^{\circ} \mathrm{C}$, and $\mathrm{FiO}_{2}$ at $21 \%$. In all subjects, body temperature was recorded every 15 min through a dedicated urinary catheter (Teleflex, Annacotty, Limerick, Ireland). We retrospectively compared these patients with 4 matched control subjects ( 2 females, median [interquartile range] age 70 [52-80] years) who were admitted to the emergency department due to primary hypothermia in the same time period, did not receive HFNC, had no respiratory failure, and had body temperature recorded with the same technique: 1:1 matching was performed solely on the basis of body temperature at admission $\pm 0.2^{\circ} \mathrm{C}$. As a standard of care in our institution, all patients received treatment with warm blankets and heated crystalloid infusion, and the treatment was continued to achieve a core body temperature of $36^{\circ} \mathrm{C}$. All patients provided informed consent to data analysis and publication.

The median [interquartile range] body temperature at admission was 32.4 [32-32.9] ${ }^{\circ} \mathrm{C}$ in both groups. In the initial $5 \mathrm{~h}$ of treatment, the median crystalloid infusion was 3.31 [2.6-3.8] in patients treated with HFNC and 3.31 [2.3-4.3] in control subjects. The median time to rewarming (defined as sustained body temperature $\geq 35^{\circ} \mathrm{C}$ ) was shorter in patients treated with HFNC: 120 [120-165] versus 345 [218-405] minutes (Mann-Whitney $p=0.026$ ). In the initial $5 \mathrm{~h}$ of treatment, the body temperature was

(c) The Author(s). 2020 Open Access This article is licensed under a Creative Commons Attribution 4.0 International License, which permits use, sharing, adaptation, distribution and reproduction in any medium or format, as long as you give appropriate credit to the original author(s) and the source, provide a link to the Creative Commons licence, and indicate if changes were made. The images or other third party material in this article are included in the article's Creative Commons licence, unless indicated otherwise in a credit line to the material. If material is not included in the article's Creative Commons licence and your intended use is not permitted by statutory regulation or exceeds the permitted use, you will need to obtain permission directly from the copyright holder. To view a copy of this licence, visit http://creativecommons.org/licenses/by/4.0/ The Creative Commons Public Domain Dedication waiver (http://creativecommons.org/publicdomain/zero/1.0/) applies to the data made available in this article, unless otherwise stated in a credit line to the data. 


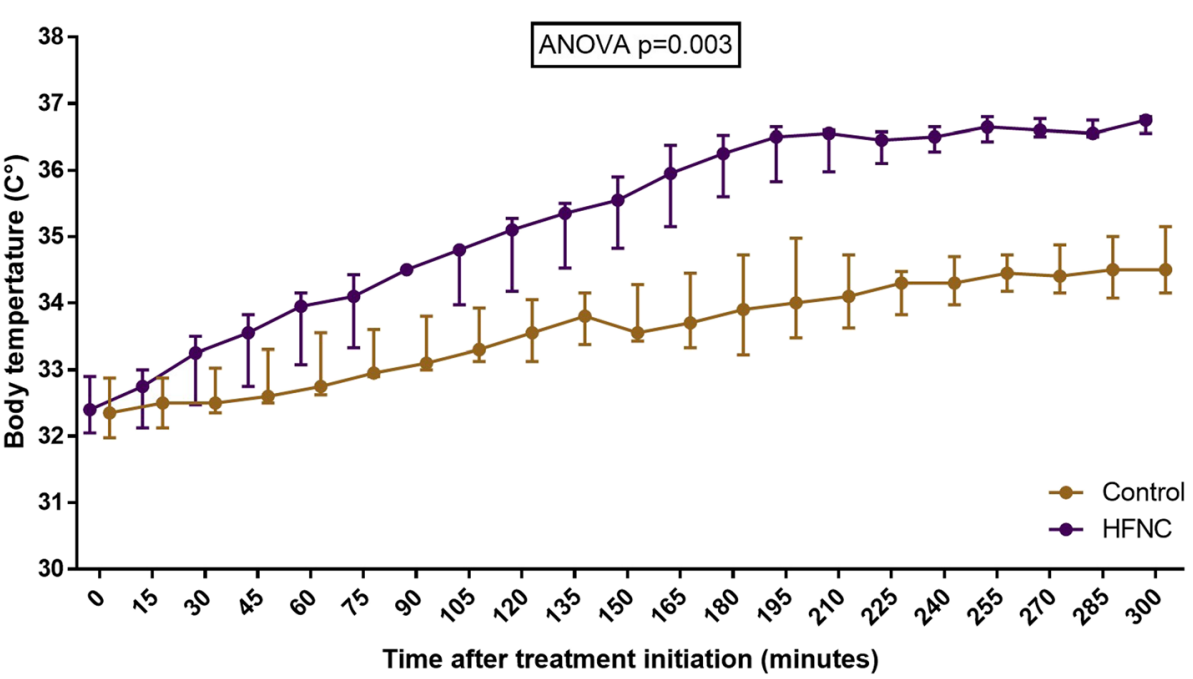

Fig. 1 Body temperature in patients treated with HFNC and in control subjects. Medians and interquartile range are displayed for each time point. Repeated measures ANOVA two-sided $p$ is reported

significantly higher in HFNC patients than in the control group: the mean inter-group difference was $1.5^{\circ} \mathrm{C}[95 \%$ confidence interval, 0.7-2.2] (repeated measures ANOVA $p=0.003$ ) (Fig. 1). Consistently with the broad safety spectrum and device tolerability of HFNC [1], no treatment-related side effects were observed.

Despite the non-randomized design of our study and the limited sample, this preliminary report suggests that heated air administration through HFNC may represent an easy-to-use tool for respiratory insulation in patients with stage 1-2 hypothermia and no signs of organ dysfunction, independently from the presence/risk of respiratory failure and gas exchange impairment.

\section{Abbreviations}

HFNC: High-flow nasal cannula; $\mathrm{FiO}_{2}$ : Fraction of inspired oxygen

\section{Acknowledgements}

None

\section{Authors' contributions}

EG and MAP designed the study. MP, KWS, and LS were involved in the patient's recruitment. DLG performed the data analysis. EG wrote the letter. MAP and DLG critically revised the manuscript. All the authors agreed on submitting the letter to Critical Care. The authors read and approved the final manuscript.

\section{Funding}

Support was provided solely from institutional and/or departmental sources.

\section{Competing interests}

DLG has received payments for travel expenses by Maquet, Getinge, and Air Liquide and is supported by grants from ESICM (2017 Draeger Award) and SIAARTI (2017 MSD award), received non-financial support by Dimar, and discloses an ongoing research grant by GE healthcare. All the other authors declare that no conflict of interest exists regarding the material discussed in the manuscript.

Received: 31 December 2019 Accepted: 19 March 2020

Published online: 30 March 2020

\section{References}

1. Papazian L, Corley A, Hess D, Fraser JF, Frat J-P, Guitton C, et al. Use of highflow nasal cannula oxygenation in ICU adults: a narrative review. Intensive Care Med. 2016:42:1336-49 Springer Berlin Heidelberg.

2. Pennisi MA, Bello G, Congedo MT, Montini L, Nachira D, Ferretti GM, et al. Early nasal high-flow versus Venturi mask oxygen therapy after lung resection: a randomized trial. Crit Care. 2019;23:68.

3. Natalini D, Grieco DL, Santantonio MT, Mincione L, Toni F, Anzellotti GM, et al. Physiological effects of high-flow oxygen in tracheostomized patients. Ann Intensive Care. 2019;9:114.

4. Lloyd EL, Croxton D. Equipment for the provision of airway warming (insulation) in the treatment of accidental hypothermia in patients. Resuscitation. 1981;9:61-5.

5. Serikov VB, Rumm MS, Kambara K, Bootomo MI, Osmack AR, Staub NC. Application of respiratory heat exchange for the measurement of lung water. J Appl Physiol. 1992;72:944-53.

6. Brown DJA, Brugger H, Boyd J, Paal P. Accidental hypothermia. N Engl J Med. 2012;367:1930-8.

\section{Publisher's Note}

Springer Nature remains neutral with regard to jurisdictional claims in published maps and institutional affiliations.

Availability of data and materials

The datasets used and/or analyzed during the current study are available from the corresponding author on reasonable request.

Ethics approval and consent to participate

Informed consent to data analysis was obtained by all studied patients. 